\begin{tabular}{|c|c|c|c|}
\hline DE & \multirow{3}{*}{$\begin{array}{l}\text { DE GRUYTER } \\
\text { OPEN }\end{array}$} & $\begin{array}{l}\text { HUNGARIAN JOURNAL OF } \\
\text { INDUSTRY AND CHEMISTRY }\end{array}$ & \multirow[t]{3}{*}{$\begin{array}{l}\text { HUUNGARIAN JOURNALI OI } \\
\text { INIDUSTRRY AND CIIIEMISTIRYY }\end{array}$} \\
\hline & & Vol. 43(2) pp. 79-83 (2015) & \\
\hline & & $\begin{array}{l}\text { hjic.mk.uni-pannon.hu } \\
\text { DOI: } 10.1515 / / \text { hjic-2015-0013 }\end{array}$ & \\
\hline
\end{tabular}

\title{
A STUDY OF THE ADSORPTION CHARACTERISTICS OF COBALT AND CAESIUM FROM A SOLUTION BY USING VIETNAMESE BENTONITE
}

\author{
Le Phuoc Cuong, ${ }^{1}$ Pham Hoang Giang, ${ }^{2}$ Bui Dang Hanh, ${ }^{3}$ And Gergö Bátor ${ }^{4 *}$ \\ ${ }^{1}$ The University of Danang-University of Science and Technology, Danang, VIETNAM \\ ${ }^{2}$ VNU University of Science, Hanoi, VIETNAM \\ ${ }^{3}$ Vietnam Atomic Energy Institute (VINATOM), Hanoi, VIETNAM \\ ${ }^{4}$ Institute of Radiochemistry and Radioecology, University of Pannonia, Veszprém, H-8201, \\ HUNGARY
}

\begin{abstract}
The radioactive waste produced from the construction of a nuclear power plant is a controversial topic. The resulting radioactive waste contains ${ }^{60} \mathrm{Co}$ and ${ }^{137} \mathrm{Cs}$ isotopes that are the most difficult to remove. Bentonite is widely used as an adsorbent for heavy metals. An important factor is the safe operation of waste management at a nuclear power plant to be built in Vietnam. Therefore, a method of degrading complexes of radionuclides and the adsorption of radionuclides onto Vietnamese Bentonite was implemented in this study. In current literature, UV radiation and heating with oxidising substances are used in general for degrading complexes of radionuclides. The experimental results for the adsorption of $\mathrm{Co}^{(\text {(II) }}$ and $\mathrm{Cs}^{+}$onto VNB suggest that VNB can be used in the future for large-scale liquid waste treatment due to its low cost, high efficiency, and environmentally friendliness.
\end{abstract}

Keywords: radionuclides; Vietnamese bentonite; adsorption; UV radiation; hydrogen peroxide

\section{Introduction}

During operation, a nuclear power plant (NPP) releases a large quantity of liquid waste containing radionuclides. The sources of liquid waste include contaminated boric acid solutions, liquid that has leaked from the primary circuit, a solution used to decontaminate the equipment of the primary circuit, and other waste sources. Radionuclides that exist in liquid waste include ${ }^{137} \mathrm{Cs},{ }^{60} \mathrm{Co},{ }^{59} \mathrm{Fe},{ }^{51} \mathrm{Cr},{ }^{54} \mathrm{Mn}$, etc. [1-4].

In all types of nuclear reactors, the solutions that are used to decontaminate equipment containing chemicals are for example, alkalis, $\mathrm{KMnO}_{4}$, EDTA, etc. [4] in order to oxidise or to form complexes with radionuclides. These complexes are highly soluble in reactor solutions. Liquid waste containing radionuclides has to be stored for a certain period of time to decay. Radionuclides with short half-lives decay during this storage time. The longer-lasting radionuclides such as ${ }^{60} \mathrm{Co}$ and ${ }^{137} \mathrm{Cs}$ are still present in concentrations above the discharge limit of $1 \mathrm{kBq} \mathrm{dm}^{-3}$. Thus, they are not allowed to be discharged into the environment even after several years of storage [5-10].

One of the most effective methods for the treatment of radioactive waste is on the basis of ion exchange and adsorption processes using inorganic ion exchangers. The desirable characteristics of high

*Correspondence: kt@almos.uni-pannon.hu exchange capacity and favourable selectivity for some radioisotopes made certain zeolites useful in the treatment of radioactive waste. Natural zeolites considered for radioactive waste treatment include mordenite, erionite, chabazite, clinoptilolite, and bentonite. Among these, bentonite has received much attention due to its widespread usage, large surface area, and high selectivity for some radiotoxic metals $[4,11]$.

Bentonite consists predominantly of the mineral montmorillonite, an aluminium hydrosilicate. Its crystal structure shows distinct layers forming a lattice (Fig.1). The term "bentonite" was first used by Knight in 1889 following the discovery of highly colloidal plastic clay near Fort Benton in the cretaceous bed of Wyoming. Bentonite is a naturally occurring cationic clay, which can be processed or modified to tailor its properties, so it is suitable for various applications and uses. In its pure form or with some chemical additives or modifications, bentonite can be used as a rotary mud, an anticaking agent for certain granular fertilisers, a binding agent in the agglomeration of cattle feed, in pesticides or mineral oil, for filling, oil deodrising, palletising or bleaching, and in civil construction, foundries, and the alkylation of phenols [4, 6-8].

The aim of this study was the identification of degrading and mineralising complex compounds of $\mathrm{Co}^{\text {(II) }}$ and $\mathrm{Cs}^{+}$by using UV radiation and heating with oxidation substances. In addition, we also determined the adsorption efficiency of these radioactive isotopes onto VNB. 


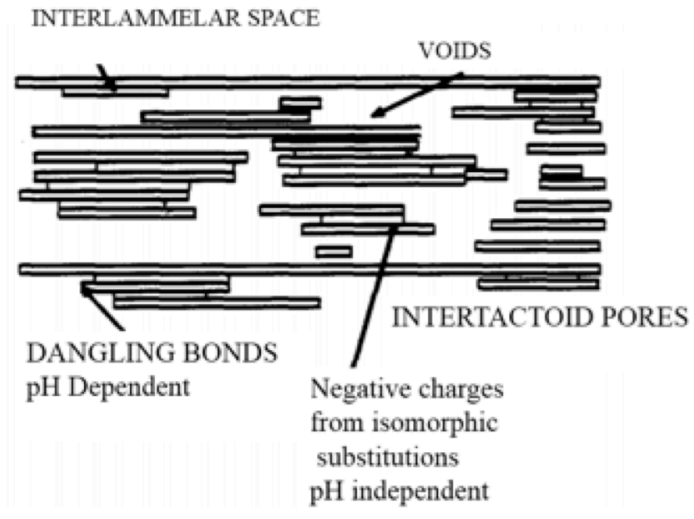

Figure 1. Structure of bentonite [6].

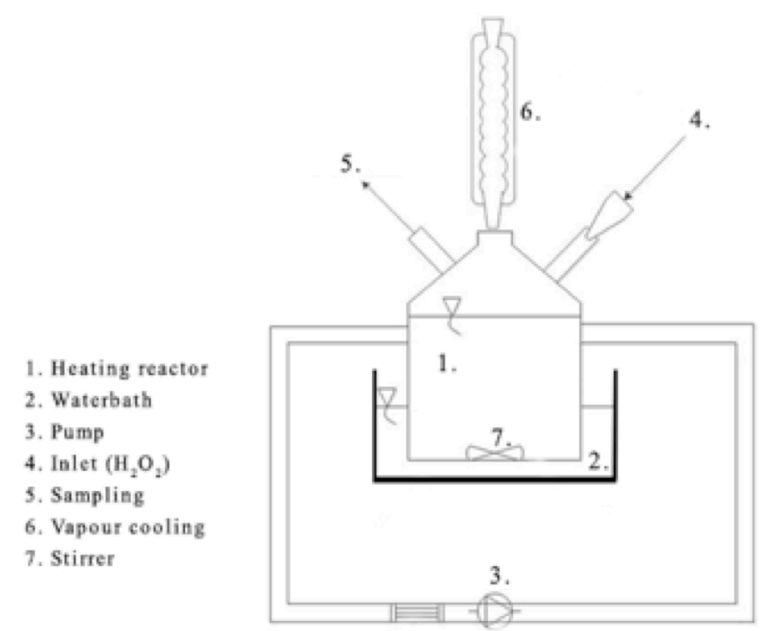

Figure 2. The experimental set-up of the heating system.

\section{Experimental}

\subsection{Objectives}

In order to extract ${ }^{60} \mathrm{Co}$ and ${ }^{137} \mathrm{Cs}$ from radioactive liquid waste, a combined treatment method was used. This method includes two stages. In the first stage, the EDTA complexed radionuclides were degraded and mineralised by UV radiation and heating with oxidising substances and then in the second stage radionuclides ions were removed by adsorption using VNB.

In order to prepare the model solutions for this study, the activity concentrations of the radioactive isotopes of ${ }^{137} \mathrm{Cs}$ and ${ }^{60} \mathrm{Co}$ in a typical liquid radioactive waste sample were determined by standard $\gamma$ spectrometry using a Gamma Múszaki Zrt scintillation (NaI) detector. Table 1 shows measurements taken from the liquid waste radioactive sample.

\subsection{Research Methodology}

The concentrations of radioactive elements were determined by using an iCE 3000 atomic absorption spectrometer (AAS, Thermo Scientific, USA) with an air- $\mathrm{C}_{2} \mathrm{H}_{2}$ flame at a flow rate of $0.9 \mathrm{dm}^{3} \mathrm{~min}^{-1}$.

The chemicals used as analytical standards were all reagent grade or better. Ethylenediaminetetraacetic
Table 1. Typical radioactive liquid waste sample (3/2/2015 measurements).

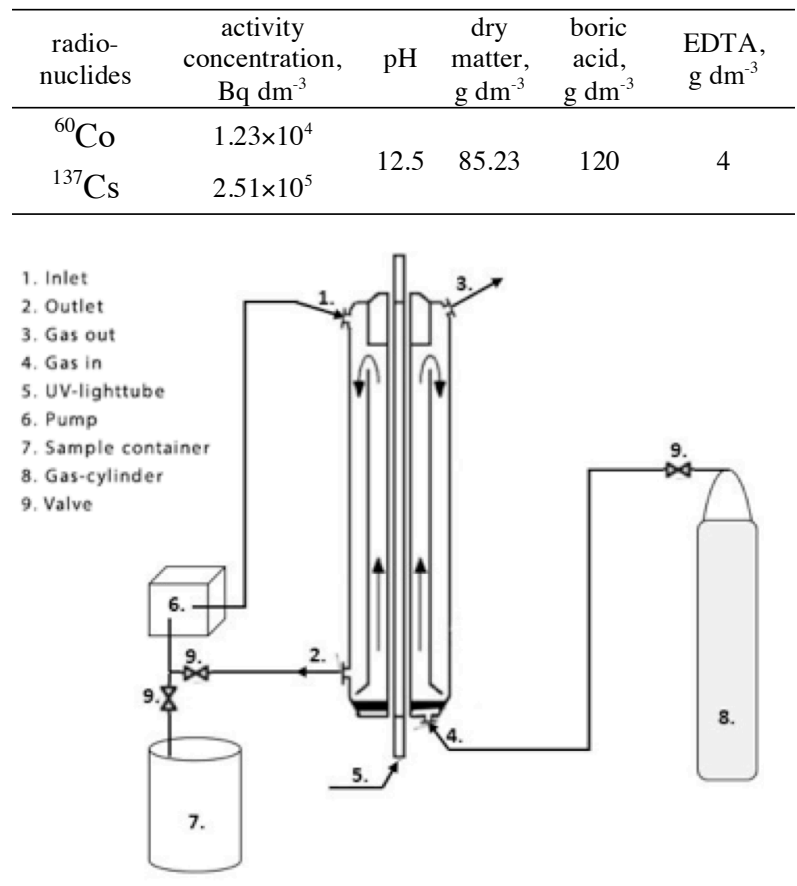

Figure 3. The experimental set-up for UV radation system.

acid (EDTA), $\mathrm{H}_{3} \mathrm{BO}_{3}, \mathrm{NaOH}, \mathrm{H}_{2} \mathrm{O}_{2}, \mathrm{CoSO}_{4}$, and $\mathrm{CsCl}$ were purchased from Merck (Germany). All glassware and polyethylene bottles were thoroughly washed and then rinsed using ultrapure water before use.

\subsubsection{Degradation of Complex Compounds by Heating with an Oxidant}

In the heated system (Fig.2), the degradation of complex EDTA, $\mathrm{CoSO}_{4}$, and $\mathrm{H}_{3} \mathrm{BO}_{3}$ was investigated under two sets of conditions at 60 and $70^{\circ} \mathrm{C}$ both with and without $\mathrm{H}_{2} \mathrm{O}_{2}$ in $30 \mathrm{mg} \mathrm{dm}^{-3}$ concentration. Each experiment lasted $1 \mathrm{hr}$ for three solutions with various concentrations of $\mathrm{CoSO}_{4}\left(10,20\right.$, and $\left.40 \mathrm{mg} \mathrm{dm}^{-3}\right)$. Aliqots of samples were taken at regular intervals, such as 10,30 , and $60 \mathrm{~min}$. These solutions were centrifuged and stirred with VNB for $1 \mathrm{hr}$. After that, the solution samples, with and without VNB, were analysed to determine the $\mathrm{Co}^{(\mathrm{II})}$ concentration.

\subsubsection{Degradation of Complexes by UV Radiation and Oxidizers}

Aspects of photocatalytic degradation of complexes with EDTA, $\mathrm{CoSO}_{4}$, and $\mathrm{H}_{3} \mathrm{BO}_{3}$ were investigated. Degradation efficiencies were studied in detail using a UV radiation system within the range of $280-315 \mathrm{~nm}$ and at $0.15 \mathrm{~W} \mathrm{~m} \mathrm{~m}^{-2}$ (Fig.3) under the following conditions:

1. only with UV light;

2. UV and $\mathrm{O}_{2}$ with flow rate of $70 \mathrm{dm}^{3} \mathrm{~h}^{-1}$ );

3. $\mathrm{UV}, \mathrm{O}_{2}$, and $\mathrm{H}_{2} \mathrm{O}_{2}$ in $3 \mathrm{mg} \mathrm{dm}^{-3}$ concentration;

4. UV, $\mathrm{O}_{2}$, and $\mathrm{TiO}_{2}$;

5. $\mathrm{UV}, \mathrm{O}_{2}, \mathrm{TiO}_{2}$ and $\mathrm{H}_{2} \mathrm{O}_{2}$. 


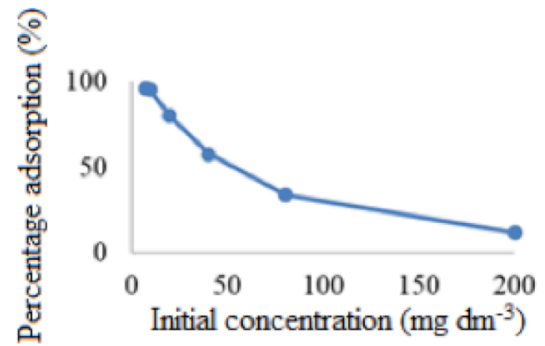

Figure 4. The effect of the initial concentration on the adsorption of $\mathrm{Co}^{(\mathrm{II})}$ onto $\mathrm{VNB}$.

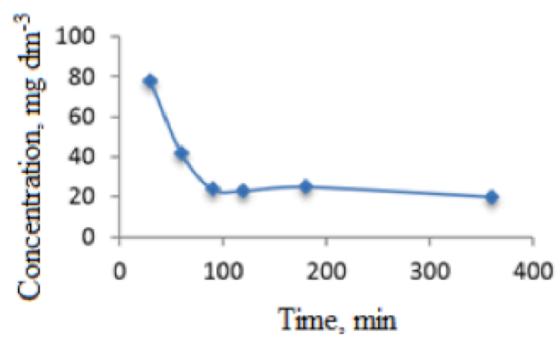

Figure $5 . \mathrm{Cs}^{+}$content in the solution after different periods of time.

Each experiment lasted for $2 \mathrm{hr}$ for the three solutions using various concentrations of $\mathrm{CoSO}_{4}(10,20$, and $40 \mathrm{mg} \mathrm{dm}^{-3}$ ). Samples were taken at regular intervals of $10,30,60$, and $120 \mathrm{~min}$. The solutions were centrifuged and stirred with VNB for $1 \mathrm{hr}$. After that, the solution samples, with and without VNB, were analysed to determine the $\mathrm{Co}^{(\mathrm{II})}$ concentration.

\subsubsection{Adsorption of Radioactive Elements onto VNB}

Experiments on the adsorption of $\mathrm{Co}^{(\mathrm{II})}$ and $\mathrm{Cs}^{+}$onto bentonite were performed in batches to determine their adsorption time and equilibrium isotherms. A volume of $30 \mathrm{~cm}^{3}$ of radioactive solution at various initial concentrations for $\mathrm{CoSO}_{4}\left(10,20\right.$, and $\left.40 \mathrm{mg} \mathrm{dm}^{-3}\right)$; and $\mathrm{CsCl}\left(60\right.$ and $120 \mathrm{mg} \mathrm{dm}^{-3}$ ) was stirred with bentonite for $1 \mathrm{hr}$ within a $\mathrm{pH}$ range of 12 to 13 , depending on the initial concentrations of EDTA and $\mathrm{H}_{3} \mathrm{BO}_{3}$ in the model solution. Samples were taken at regular intervals, centrifuged, and the concentration of $\mathrm{Co}^{\text {(II) }}$ and $\mathrm{Cs}^{+}$ions were measured.

\subsubsection{Adsorption Isotherms}

To evaluate the adsorption ability of ions onto bentonite, the Langmuir and Freundlich isotherm models were employed. On the basis of experimental data, the typical parameters of the adsorption process were determined by using the linear regression method. The Langmuir equation is given by:

$$
q_{\mathrm{e}}=q_{\mathrm{m}} k_{\mathrm{a}} C_{\mathrm{e}} /\left(1+K_{\mathrm{a}} C_{\mathrm{e}}\right) .
$$

Its linear form is

$$
C_{\mathrm{e}} / q_{\mathrm{e}}=\left(1 / q_{\mathrm{m}}\right) C_{\mathrm{e}}+1 /\left(K_{\mathrm{a}} q_{\mathrm{m}}\right)
$$

where $q_{\mathrm{e}}$ is the amount of ions adsorbed $\left(\mathrm{mg} \mathrm{g}^{-1}\right)$ at equilibrium; $C_{\mathrm{e}}$ is the equilibrium concentration (mg $\left.\mathrm{dm}^{-3}\right) ; q_{\mathrm{m}}$ is the maximum adsorption capacity $\left(\mathrm{mg} \mathrm{g}^{-1}\right)$; and $K_{\mathrm{a}}$ is the adsorption equilibrium constant. A plot of $C_{\mathrm{e}} / q_{\mathrm{e}}$ against $C_{\mathrm{e}}$ expected to give a straight line with a gradient of $1 / q_{\mathrm{m}}$ and an intercept of $1 /\left(K_{\mathrm{a}} q_{\mathrm{m}}\right)$. The Freundlich equation is given by:

$$
q_{\mathrm{e}}=K_{\mathrm{f}} C_{\mathrm{e}}^{1 / \mathrm{n}} .
$$

Its linear form is:

$$
\ln q_{\mathrm{e}}=\ln K_{\mathrm{f}}+(1 / n) \ln C_{\mathrm{e}}
$$

where $K_{\mathrm{f}}$ and $n$ are constants.

\section{Results and Discussion}

\subsection{Efficiency of the Adsorption of Radioactive Elements onto VNB}

For the estimation of the adsorption ability of $\mathrm{Co}^{(\mathrm{II})}$ onto VNB, $0.1 \mathrm{~g}$ of VNB was stirred with $50 \mathrm{~cm}^{3}$ of $\mathrm{Co}^{\text {(II) }}$ solution (8-200 $\mathrm{mg} \mathrm{dm}^{-3}$ ). After equilibrium was achieved, the residual concentration of $\mathrm{Co}^{(\mathrm{II})}$ was measured using an iCE 3000 AAS (atomic absorption spectrometer).

The effect of initial concentrations on the adsorption of $\mathrm{Co}^{(\mathrm{II})}$ by VNB can be seen in Fig.4. When the initial $\mathrm{Co}^{(\mathrm{II})}$ concentration was increased from 8 to $200 \mathrm{mg} \mathrm{dm}^{-3}$ the absolute amount of $\mathrm{Co}^{(\mathrm{II})}$ adsorbed per unit weight of VNB increased from $2.31 \mathrm{mg} \mathrm{g}^{-1}(96.5 \%)$ to $6.95 \mathrm{mg} \mathrm{g}^{-1}(11.8 \%)$. However, the percentage adsorption decreased with increasing initial concentration. The results showed that at higher initial concentrations, the number of available adsorption sites decreased and hence, the removal of $\mathrm{Co}^{(\text {II) }}$ ions depends upon the initial concentration.

To determine the optimal reaction time in order to achieve an equilibrium state, flasks containing a mix of solutions $\left(\mathrm{CsCl}, \mathrm{NaOH}, \mathrm{H}_{3} \mathrm{BO}_{3}\right)$ with $\mathrm{VNB}$ were stirred for different periods of time $(10,30,60$, and $120 \mathrm{~min})$. The concentrations of $\mathrm{Cs}^{+}$ions in the solutions were measured using an atomic absorption spectrometer. The reaction time required to achieve an equilibrium state was defined between the start of stirring and when the analyte concentration remained constant. Fig.5 describes the $\mathrm{Cs}^{+}$content in the solution after different periods of time. According to Fig.5, a period of $100 \mathrm{~min}$ can be considered optimal reaction time to achieve equilibrium. This optimal time was implemented for the experiments on the adsorption of $\mathrm{Cs}^{+}$ions onto VNB.

\subsection{Study of the Kinetics of the Adsorption of Radionuclides onto Bentonite}

\subsubsection{Adsorption Isotherms of $\mathrm{Co}^{(\mathrm{II})}$}

Fig.6 shows the adsorption isotherms of $\mathrm{Co}^{\text {(II) }}$ onto VNB, which can be described by the Langmuir model with a correlation coefficient $\left(R^{2}\right)$ of 0.9791 and a maximum adsorption capacity of $8.15 \mathrm{mg} \mathrm{g}^{-1}$. The equilibrium data also corresponded to the Freundlich isotherm with a correlation coefficient $\left(R^{2}\right)$ of 0.9640 . 

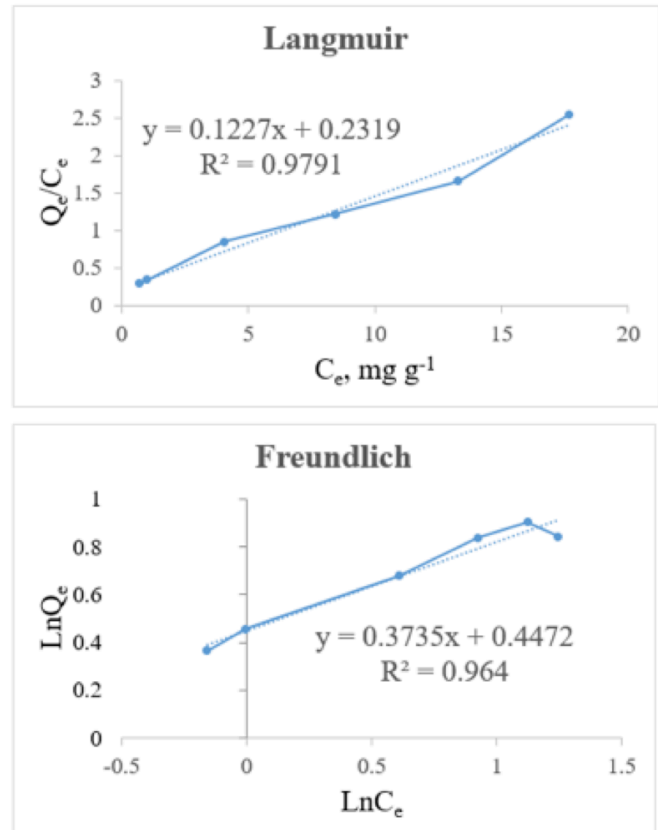

Figure 6. Adsorption Isotherms of $\mathrm{Co}^{(\mathrm{II})}$ onto VNB.
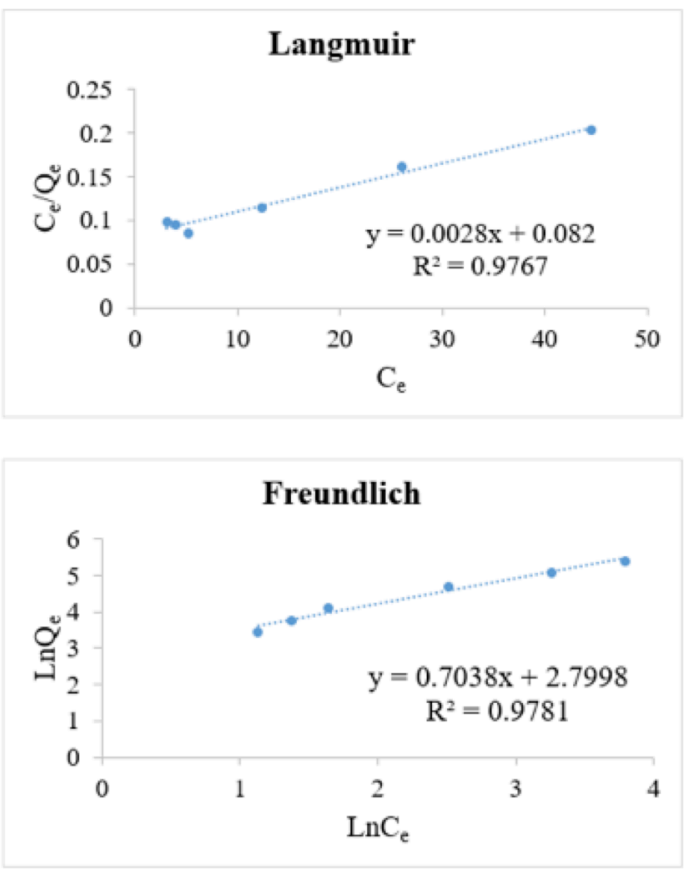

Figure 8. Adsorption Isotherms of $\mathrm{Cs}^{+}$onto VNB.

Regarding the four experiments with heating, only Exp. 4 with reaction at $90^{\circ} \mathrm{C}$ and $30 \mathrm{mg} \mathrm{dm}^{-3}$ of $\mathrm{H}_{2} \mathrm{O}_{2}$ could reduce the concentration of $\mathrm{Co}^{(\mathrm{II})}$ otherwise the $\mathrm{Co}^{\text {(II) }}$ concentration remained unchanged or showed no significant change. Fig.7 shows that the concentration of $\mathrm{Co}^{(\mathrm{II})}$ decreased as time increased within 30 minutes, but after that, it practically remained constant. Moreover, initial concentrations also affected the efficiency of removing $\mathrm{Co}^{\text {(II) }}$ with initial concentrations of 10,20 , and $40 \mathrm{mg} \mathrm{dm}^{-3}$. The corresponding efficiency values for removing $\mathrm{Co}^{(\mathrm{II})}$ were $22.2 \%, 31.5 \%$ and $61.7 \%$, respectively for samples that were not stirred with VNB, and $22.7 \%, 43.3 \%$, and $67.7 \%$ for samples that were stirred with VNB.

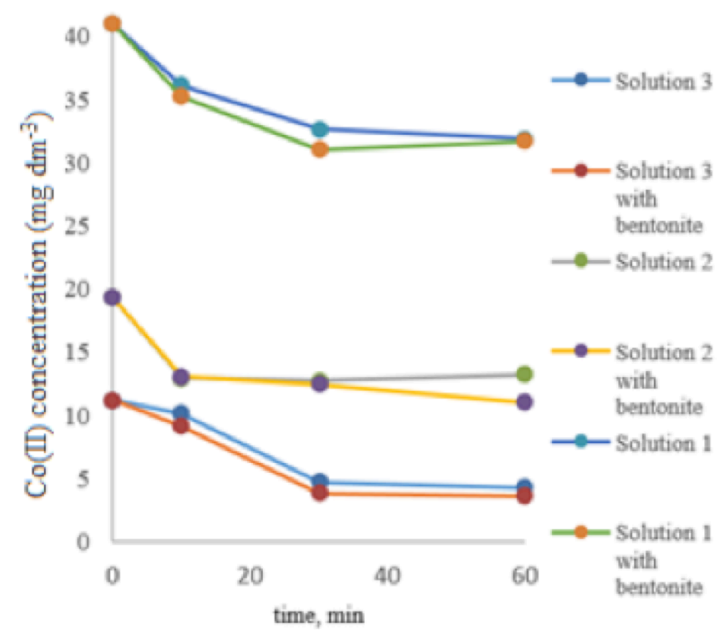

Figure 7. Degradation of $\mathrm{Co}^{(\mathrm{II})}$ over different time periods (Ex. 4) using solution 1: $40 \mathrm{mg} \mathrm{dm}^{-3} \mathrm{Co}^{(\mathrm{II})}$; solution 2: $20 \mathrm{mg} \mathrm{dm}^{-3} \mathrm{Co}^{\text {(II) }}$; and solution $3: 10 \mathrm{mg}$ $\mathrm{dm}^{-3} \mathrm{Co}^{(\mathrm{II})}$.

Thus, the experimental adsorption capacity of VNB indicate that it can adsorb $\mathrm{Co}^{(\mathrm{II})}$ at the highest value of adsorption capacity of $8.15 \mathrm{mg} \mathrm{g}^{-1}$, but in the four experiments with heating, the efficiency of removing $\mathrm{Co}^{\text {(II) }}$ with $\mathrm{VNB}$ did not show significant differences without VNB. Previous research [2, 4, 6] showed that bentonite exhibits good adsorption capacities toward organic matter. However, these results showed that the adsorption ability of EDTA onto bentonite is low, and $\mathrm{Co}^{\text {(II) }}$ still remains complexed with EDTA. It is removed only when EDTA is completely degraded.

With regard to the UV system, the results from all experiments show that the outcome of this method was not affected by decreasing $\mathrm{Co}^{(\mathrm{II})}$ concentration. Rekab et al. showed [2] that the efficiencies of $\mathrm{UV} / \mathrm{TiO}_{2}$ and $\mathrm{UV} / \mathrm{H}_{2} \mathrm{O}_{2}$ treatments are $67 \%$ and $42 \%$, respectively at low $\mathrm{pH}$. On the other hand, the degradation efficiency was greater under acidic $\mathrm{pH}$ conditions, likely due to the dissociation of $\mathrm{H}_{2} \mathrm{O}_{2}$ into $\mathrm{HO}_{2}^{-}$at alkaline $\mathrm{pH}$, and the photolytic generation of $\mathrm{OH}^{*}$ radicals is therefore hindered. The amine functional groups in EDTA is dominantly converted to ammonia, which forms a complex compound with $\mathrm{Co}^{\text {(II) }}$ [2].

\subsection{Adsorption Isotherms of Cs}

Fig.8 shows that the adsorption isotherm of $\mathrm{Cs}^{+}$onto VNB could be described by both the Langmuir and Freundlich models with correlation coefficients $\left(R^{2}\right)$ of 0.98 for both respectively. On the basis of both of these models, the highest value of adsorption capacity was $1.15 \mathrm{mg} \mathrm{g}^{-1}$ showing that VNB can adsorb Cs.

\section{Conclusion}

VNB was tested as an adsorbent material for the removal of cobalt and caesium ions from sulphate and chloride waste solutions. The adsorption of $\mathrm{Co}^{\text {(II) }}$ ions 
onto VNB followed the pseudo-second order rate model. The adsorption isotherm of $\mathrm{Co}^{\text {(II) }}$ was described by the Langmuir and Freundlich models. These show that radioactive isotopes can be highly efficiently adsorbed onto VNB. The adsorption isotherm of $\mathrm{Cs}^{+}$ corresponded to both the Freundlich and Langmuir models with high correlation coefficients. In the presence of EDTA in radioactive waste solution, radioactive isotopes could not be adsorbed onto VNB due to forming stronger complexes with EDTA Therefore, in this study two pre-treatment systems were implemented to remove EDTA from the liquid waste. Heating achieves an efficiency of $67 \%$ while the UV radiation did not exhibit satisfactory improvement of treatment efficiency. We are planntng to scale up the $\mathrm{UV}$ system to include the optimisation of $\mathrm{pH}$ values and the effect of ammonium converted from EDTA in order to apply these findings to radioactive solution waste on a large scale.

\section{Acknowledgement}

The authors would like to thank the Ministry of Education and Training, Vietnam for funding this research, and the Institute of Radiochemistry and Radioecology at the University of Pannonia for providing the experimental conditions.

\section{REFERENCES}

[1] Manohar, D.; Noeline, B.; Anirudhan, T.: Adsorption performance of Al-pillared bentonite clay for the removal of cobalt(II) from aqueous phase, Applied Clay Science, 2006, 31(3-4), 194 206 DOI: 10.1016/j.clay.2005.08.008

[2] Rekab, K.; Lepeytre, C.; Dunand, $\mathrm{M} .: \mathrm{H}_{2} \mathrm{O}_{2}$ and/or photocatalysis under UV-C irradiation for the removal of EDTA, a chelating agent present in nuclear waste waters, Appl. Cat. A: General, 2014, 488(11), 103-110 DOI: 10.1016/j.apcata.2014.09.036
[3] Omar, H.; Arida, H.; Daifullah, A.: Adsorption of ${ }^{60} \mathrm{Co}$ radionuclides from aqueous solution by raw and modified bentonite, Appl. Clay Sci., 2009, 44(1), 21-26 DOI: 10.1016/j.clay.2008.12.013

[4] Egamediev, S.Kh.; Nurbaeva, D.A.; Tashtemirova, N.G.: Modified bentonite as adsorbents for radionuclides: adsorption of carrier-free radiocobalt-57 on acid modified and calcined bentonite, Proc. Int. Conf. "Nuclear Science and its Application", Samarkand, Uzbekistan, September 25-28, 2012, pp. 345-346 INIS: RN:44129011

[5] IAEA: Modified Combined Methods for liquid radioactive waste treatment, Final Report (Int. Atomic Energy Agency, TECDOC-1336) 19972001 ISSN: 1011-4289

[6] Dale Ortego, J.; Kowalska, M.; Cocke, D.: Interactions of montmorillonite with organic compounds - adsorptive and catalytic properties, Chemosphere, 1991, 22(8), 769-798 DOI: 10.1016/0045-6535(91)90052-F

[7] Milyuin, V.V.; Kononenko, O.A.: Sorption of caesium on finely dispersed composite ferrocyanide sorbents, Radiochem., 2010, 52(3), 281-283 DOI: $10.1134 / \mathrm{S} 1066362210030100$

[8] Tofalvi, R.; Sepsey, A.; Horvath, K.; Hajos, P.: Environmental significance and identification of metal-chelate complexes using ion chromatography, Hung. J. Ind. Chem., 2011, 39(1), 95-99

[9] Frerich, J.K., Flugge, U.: High performance catalytic tubular membrane reactors owing to forced convective flow operation, Hung. J. Ind. Chem., 2005, 33(1-2), 31-42

[10] Varga, K.; Hirschberg, G.: Accumulation of radioactive corrosion products on steel surface of VVER-type nuclear reactors. II. ${ }^{60} \mathrm{Co}, \mathrm{J} . \mathrm{Nucl}$. Mater., 2001, 298(3), 231-238 DOI: 10.1016/S00223115(01)00658-4

[11] Kolics, A.; Varga, K.: Study of cobalt sorption on polyethylene, J. Colloid Interface Sci., 1994, 168(2), 451-457 DOI: 10.1006/jcis.1994.1441 